\title{
Metodologia IRDI nas creches: relato de experiência na rede pública \\ e privada
}

\section{IRDI Methodology in day care centers: report of experience in the public and private day care center}

\author{
Ana Paula Magosso Cavaggioni' ${ }^{1}$, Michelle Cristine Tomaz de Oliveira² ${ }^{2}$ Miria \\ Benincasa $^{3}$
}

\begin{abstract}
Resumo
Houve um aumento significativo no número de crianças de 0 a 3 anos que frequentam Centros de Educação Infantil (CEIs), o que torna fundamental a análise das consequências da coletivização precoce no desenvolvimento subjetivo das crianças. Este artigo descreve a experiência de acompanhamento de educadoras de bebês de 0 a 18 meses de idade, a partir da metodologia IRDI, realizada em dois CEIs: um da rede conveniada e outro da rede privada. O objetivo foi observar o impacto das diferenças encontradas nestas instituições em relação ao ambiente e ao cuidado com os bebês em seu desenvolvimento psíquico. Este artigo é um recorte da pesquisa Metodologia IRDI: uma intervenção com educadores a partir da psicanálise, desenvolvida em 2012 e 2013. Analisaram-se os IRDIs iniciais e finais de 17 crianças acompanhadas nessas instituições, bem como o resultado da Avaliação Psicanalítica aos 3 anos (AP3), articulando estes dados com as diferenças observadas nas duas instituições.

Palavras-chave: Creche. IRDI. Desenvolvimento infantil. Psicanálise.
\end{abstract}

\begin{abstract}
There was a significant increase in the number of children aged 0 to 3 attending Early Childhood Centers (CEIs), making it fundamental to analyze the consequences of early collectivization in the subjective development of children. This article describes the experience of accompanying educators of babies from 0 to 18 months of age, based on the IRDI methodology carried out in two CEIs - one from the network and another from the private network, - in order to observe the impact of the differences found in these institutions in relation to the environment and the care of the babies in their psychic development. This article is a cut-off from the IRDI Methodology research: an intervention with educators from psychoanalysis, developed in 2012 and 2013. We analyzed the initial and final IRDIs of 17 children followed at these institutions, as well as the result of the Psychoanalytic Assessment at 3 years (AP3), articulating these data with the differences observed in both institutions.

Keywords: Day care. IRDI. Child development. Psychoanalysis.
\end{abstract}

\footnotetext{
1 Psicóloga, Doutoranda em Psicologia da Saúde pela Universidade Metodista de São Paulo - UMESP. E-mail: anapaulamagosso@ gmail.com

2 Psicóloga, pesquisadora bolsista FAPESP pelo grupo de pesquisa sobre Desenvolvimento do Bebê.

3 Doutora em Psicologia Humana pela Universidade de São Paulo - USP. Docente na Pós-Graduação Stricto Sensu em Psicologia da Saúde da Universidade Metodista de São Paulo - UMESP.
} 


\section{Introdução}

Atualmente, encontramos em vários estados brasileiros três espaços diferentes destinados ao atendimento de crianças de 0 a 3 anos de idade: os Centros de Educação Infantil (CEIs) diretos, os CEIs conveniados e os CEIs particulares que são pertencentes à iniciativa privada. Tanto os CEIs diretos como os conveniados prestam atendimento público. A diferença entre ambos está na administração: os primeiros são administrados diretamente pelo Estado, enquanto os segundos o são por entidades conveniadas ao estado. Como são atendidas as crianças nestes diferentes contextos? Estas instituições apresentam condições semelhantes de atender às necessidades das crianças, necessidades estas voltadas não apenas aos cuidados de saúde, higiene, segurança e educação, mas também àquelas relacionadas ao desenvolvimento psíquico? O objetivo deste trabalho consiste em descrever e analisar a experiência vivida em duas instituições, um CEI conveniado e um CEI particular, analisando as diferenças encontradas e os possíveis impactos na constituição subjetiva das crianças por elas atendidas.

\section{O Surgimento das Creches}

A compreensão das raízes históricas referente ao surgimento das creches, hoje denominadas Centros de Educação Infantil (CEIs), é necessária para que se possa visualizar de que maneira o fenômeno educativo foi se estruturando na rede pública e privada. A primeira creche foi criada na França pelo padre Oberlin, no século XIX, com objetivo de atender às crianças pequenas provenientes das classes de baixa renda que comumente permaneciam sozinhas e desamparadas enquanto os pais enfrentavam suas longas jornadas de trabalho. Foi, portanto, com caráter assistencial higienista voltado a esta população que as creches foram surgindo ao redor do mundo (ABRAMOWICZ; WASKOP, 1995; CIVILETTI, 1991).
No Brasil, as creches surgiram por volta de 1870 com objetivo não apenas de atender os filhos das mulheres que precisavam trabalhar para complementar a renda familiar, mas também os filhos de empregadas domésticas. Desde o seu surgimento estiveram, também, estreitamente relacionadas ao atendimento da população de baixa renda, promovendo um trabalho de cunho essencialmente assistencial, voltado às necessidades relacionadas à alimentação, higiene, saúde e segurança dessas crianças. (CAMPOS; ROSEMBERG; FERREIRA, 1993; FARIA, 1997; OLIVEIRA, et al., 1992).

Até 1920, o atendimento em creches era essencialmente filantrópico. Com a crescente industrialização e os movimentos operários, além do interesse em disciplinar os trabalhadores, é que foram criadas as primeiras creches junto às indústrias destinadas aos filhos de operárias durante o período de trabalho. A legislação trabalhista de 1943 determinou que as empresas que contassem com mais de 30 funcionárias oferecessem a creche aos seus filhos, numa tentativa de isentar o Estado de qualquer responsabilidade. Apesar desta exigência, porém, as creches permaneceram ainda, essencialmente, sob a responsabilidade de entidades filantrópicas e religiosas até meados do século XX. (OLIVEIRA, 1988; ROSEMBERG, 1989). A partir da história do surgimento das creches no Brasil, é possível observar que estas não foram criadas para atender as necessidades das crianças pequenas, mas em resposta à necessidade da mulher se incorporar no mercado de trabalho (CATALDI, 1992).

Por volta de 1970, houve um desenvolvimento intenso no setor privado da educação pré-escolar destinada às classes média e alta. Essas se diferenciavam das creches existentes até então por seu caráter pedagógico e de cuidado com o desenvolvimento infantil em seus aspectos cognitivos, emocionais e sociais. Paralelamente, nos grandes centros urbanos passou a haver intensa reivindicação da população por creches de qualidade, especialmente através da pressão de alguns movimentos em áreas de periferia - como 
o movimento feminista, a pastoral da criança e sociedade de amigos do Bairro - exigindo-a como um direito do trabalhador, dever do Estado e como espaço de educação adequado às crianças pequenas (OLIVEIRA, 1988; ROSEMBERG, 1989).

A Constituição de 1988, concomitante ao surgimento da democracia, foi fundamental para ampliar a visão de creche prevalente até então e garantir a educação de qualidade de crianças pequenas como direito da criança, opção da família e dever do Estado. Em 1996, com a nova Lei de Diretrizes e Bases da Educação LDB (n. 9394/96), a creche passou a ser incluída como parte da educação infantil e responsável pelas crianças de 0 a 3 anos de idade (BRASIL, 1996).

O Estado, porém, foi incapaz de suprir a demanda da população por vagas em creches. Com isso, as prefeituras criaram o projeto de creches conveniadas com o objetivo de ampliar a oferta de vagas. A creche conveniada consiste em uma parceria estabelecida entre a Prefeitura e entidades sociais, filantrópicas ou religiosas que, segundo a portaria 3477/11:

Devem ser entendidos como espaços coletivos privilegiados de vivência da infância, que visam contribuir na construção da identidade social e cultural das crianças, fortalecendo o trabalho integrado do cuidar e do educar, numa ação complementar à da família e da comunidade, objetivando proporcionar condições adequadas para promover educação, proteção, segurança, alimentação, cultura, saúde e lazer, com vistas à inserção, prevenção, promoção e proteção à infância (SÃO PAULO, 2011).

Observa-se que, ao longo dos anos, foi se modificando a ideia da creche como um local de atendimento apenas à população de baixa renda. O número de creches e escolas maternais em todas as classes sociais foi aumentando e estas passaram a ser frequentadas também por filhos de mulheres que não trabalhavam fora, mas que buscavam estes espaços para colaborar com a socialização e educação de seus filhos (CAMPOS; ROSEMBERG; FERREIRA, 1993). O fato de várias famílias, provenientes de diferentes classes sociais, inserirem seus filhos em creches colaborou para que estas se tornassem, pelo menos em teoria, um equipamento e um direito, sobretudo, educativo.

Ao longo da última década, pode-se observar um aumento significativo da inserção de crianças de 0 a 3 anos de idade nas creches (IBGE, 2010) que permanecem nestes espaços por períodos de $8 \mathrm{~h}$ a 12 horas diárias (DIEESE, 2007). Entre 2000 e 2010, foi observado um aumento de $150 \%$ no número de crianças inseridas em creches. Em 2000, eram atendidas 9,4\% das crianças até 3 anos nas CEIs. Em 2010, este número subiu para 28,2\% (BRASIL, 2012). O crescente número de entrada de bebês nos CEIs, principalmente durante o primeiro ano de vida, implica em separações precoces e diárias do bebê de sua mãe em uma fase em que esta relação particularizada é base para a constituição psíquica do bebê (MARIOTTO, 2009).

\section{O Bebê e a Creche}

Pesquisas contemporâneas em neurociências demonstram que as experiências afetivas vividas pelo recém-nascido afetam tanto seu desenvolvimento emocional quanto seu desenvolvimento cognitivo (VERNY; WEINTRAUB, 2014). Da mesma forma, a psicanálise vem cada vez mais se dedicando ao estudo e compreensão das fases iniciais da vida do ser humano em virtude do reconhecimento de que as mais primitivas experiências do bebê, bem como a qualidade de suas primeiras relações, servirão de protótipo para as relações posteriores. Em outras palavras, as experiências originais vividas podem dar lugar a uma vida mental saudável ou a situações de sofrimento psíquico segundo a qualidade de suas primeiras relações.

Tal fato já foi comprovado por inúmeros teóricos, dentre eles John Bowlby (1989). Ele desenvolveu seu trabalho baseando-se na etologia, 
na teoria da evolução e na psicologia cognitiva. Em 1951, a partir de um estudo solicitado pela OMS, Bowlby desenvolveu a teoria do apego na qual postula a existência de uma organização psicológica interna situada no sistema nervoso central. Esta, segundo o autor, seria a responsável pela formação e manutenção dos laços emocionais íntimos entre indivíduos. Suas pesquisas demonstraram que a propensão em estabelecer laços é considerada um componente básico da natureza humana, tal como a alimentação e o sexo. Esta propensão se encontra presente no neonato em forma germinal e seus primeiros laços persistem e são complementados por novos, estendendo-se pela vida até a velhice. Sendo assim, a vivência afetiva do bebê influencia de forma determinante seu desenvolvimento ao longo da vida e se encontra na base do desenvolvimento da personalidade e da saúde mental. Suas pesquisas ressaltam a importância dos cuidados, especialmente o cuidado materno, e da vivência desses cuidados que constituem as primeiras experiências afetivas do bebê.

O autor afirma que uma personalidade estável e autoconfiante se constitui a partir dos vínculos estabelecidos com as figuras de apego e que muitas patologias podem ser atribuídas à privação ou descontinuidade deste contato afetivo e amoroso durante os primeiros anos de vida. Da mesma forma, segundo ele, a privação de afeto adequado e da relação amorosa com os cuidadores, mesmo que parcial, pode gerar sentimentos como: angústia, exagerada necessidade de amor, fortes sentimentos de vingança, culpa e depressão (BOWLBY, 1988).

Uma pesquisa pioneira realizada por René Spitz (1945), comparou o desenvolvimento psicoafetivo em dois grupos distintos: um grupo de filhos de mães presidiárias no qual cada mãe, apesar de suas condições, cuidava do filho durante o dia com o auxílio de uma enfermeira; outro, composto por crianças criadas em orfanatos que recebiam cuidados de higiene e alimentação adequados para sua sobrevivência, porém, careciam de qualquer contato humano caloroso durante a maior parte do dia.
Spitz (1945) observou a reação de "hospitalismo" (reações dos bebês à separação do contato afetivo e amoroso com a mãe que podem comprometer seu desenvolvimento biológico e psíquico, causando ainda depressão anaclítica) na segunda população, enquanto na primeira tal reação apareceu apenas após uma separação da mãe que era quem lhes provia o afeto. Ou seja, mesmo tendo garantidos os cuidados de higiene e alimentação, as crianças da segunda população apresentaram retardo físico, social e intelectual, com sinais de uma deterioração progressiva que envolveu toda a criança e que mostrou sinais desde muito cedo. Os relevantes resultados de sua pesquisa levaram à primeira reforma de hospitalização de crianças pequenas e, a partir de 1950, a OMS passou a incluir em suas orientações um documento de nome "Cuidados Maternos e Saúde Mental". Este documento reforça o papel essencial que tem os cuidados maternos no decurso da primeira infância para o desenvolvimento harmonioso da saúde mental e cognitiva da criança.

$\mathrm{O}$ autor afirma ainda que:

"Pode ocorrer atraso motor e algumas crianças tornam-se passivas. Neste tipo de crianças, há uma progressiva e crescente predisposição à infecção, além de uma alta porcentagem de marasmo e morte. Tais crianças têm dificuldades de vestirem-se sozinhas, problema de controle dos esfíncteres, bem como vocabulário pobre" (SPITZ, 1980, p. 242).

Winnicott (1978) também afirma que a base da saúde mental é estabelecida nos primórdios da infância por meio dos cuidados dispensados ao bebê por uma mãe "suficientemente boa", propondo que a psique só pode originar-se dentro de um determinado enquadre. Considera que os primórdios da vida do bebê são uma etapa especialmente delicada do desenvolvimento, de cujo sucesso depende o estabelecimento da saúde ou da psicose.

Dessa forma, a entrada da criança na creche consiste, na maioria dos casos, na primeira separação desta de sua família. A criança é inserida em uma coletividade que impõe a lei paterna, limites e uma 
rotina preexistente que não considera seus desejos e necessidades individuais, em um momento muito importante de seu desenvolvimento psíquico (VASCONCELOS et al., 2003).

Ao longo das últimas décadas, pesquisas vêm demonstrando que o período de adaptação nas creches é estressante para os bebês e para as crianças pequenas, segundo a visão de mães e educadoras. A separação diária da mãe e sua ausência durante a maior parte do dia, o contato com pessoas novas, o ambiente novo, a mudança na rotina e na alimentação impõem ao bebê uma intensa exigência social e emocional para a qual, muitas vezes, não está preparado (DAVIES; BREMBER, 1991). Esse estresse, provocado pela situação nova, é vivenciado tanto pelo bebê como pela educadora que o recebe e pela família, pois implica em reorganizações para todos os envolvidos.

Os adultos envolvidos nas adaptações a essas novas situações influenciam e são influenciados pelas reações da criança. Uma adaptação gradual, que possa contar com a presença do cuidador principal junto à criança enquanto ela se habitua a este novo contexto, pode auxiliá-la no estabelecimento de uma boa relação com as educadoras e com os pares (BALABAN, 1988; BLOOM-FESHBACH; COLS, 1980). Porém, sabe-se que esta não é uma prática difundida em todos os CEIs (RAPOPORT; PICCININI, 2000).

Winnicott (1982b) defende a existência de um potencial inato no ser humano rumo ao desenvolvimento e integração que faz parte do processo de maturação. Porém, o fato de ser inato não garante sua ocorrência. Esta dependerá, também, de um ambiente facilitador, suficientemente bom e que responda às necessidades de cada criança. Portanto, o ambiente, em especial o ambiente inicial da criança, exerce um papel fundamental para o desenvolvimento psíquico. Esse ambiente inicial é, geralmente, representado pela mãe (ou substituto) e pela creche ao longo dos 2 primeiros anos de vida da criança. Neste período, a criança ultrapassa as fases de "dependência absoluta" (que perdura até aproximadamente 6 meses de idade) e de "dependência relativa" (aproximadamente dos 6 meses aos 2 anos de idade) e segue rumo à fase de "independência".

No período em que normalmente os bebês começam a frequentar os CEIs, por volta dos 4 meses de idade, eles se encontram na fase de dependência absoluta. Nesta fase eles não são capazes de diferenciar o meio de si próprio e ainda é importante a manutenção da ilusão. Esta ilusão faz parte da relação inicial mãe-bebê e é oferecida normalmente por uma mãe suficientemente boa, presente e atenta às suas necessidades, condição difícil de ser mantida em um ambiente coletivo no qual 2 educadoras precisam atender simultaneamente a 14 bebês. Da mesma forma, nesta fase, eles necessitam que lhes sejam oferecidos o holding (que se refere à rotina de cuidados cotidianos que dão suporte corporal e psíquico à criança) e o handling (que se refere à manipulação do bebê durante os cuidados físicos, que o personaliza), também difíceis de serem mantidos sem a dedicação praticamente exclusiva de um adulto às suas necessidades. Estas 3 condições - ilusão, holding e handling - são importantes para que o bebê caminhe para a fase de dependência relativa. Nesta fase já se tornam capazes de tolerar certa desilusão, decorrente das falhas inevitáveis da mãe ou do cuidador, e de perceber uma realidade separada de si. Neste momento, ao se deparar com uma realidade que seja intensa, o bebê já tem condições de recorrer a um espaço transicional que o protege do que ainda não possui recursos para tolerar. Os cuidados físicos com a criança promovem a integração ao mundo psíquico, auxiliando-a no estabelecimento de relações objetais e no processo de diferenciação do outro (WINNICOTT, 1982b).

Um holding e um handling deficientes em virtude da troca constante de educadores nos CEIs; a falta do cuidado de qualidade como necessita o bebê, uma vez que os educadores ficam sobrecarregados com vários bebês sob seus cuidados; a presença de fatores negativos para o seu desenvolvimento, como 
sons altos, por exemplo, são fatores que dificultam o caminho do bebê rumo à integração, e podem levá-lo ao enfraquecimento egóico (WINNICOTT, 1982b). Desta forma, é fundamental que os educadores de CEIs tenham não apenas condições de exercer o trabalho com as especificidades necessárias aos cuidados com crianças pequenas, mas que também reconheçam a importância de seu papel e sua função no desenvolvimento e na saúde psíquica das mesmas (VASCONCELOS et al., 2003).

Os CEIs devem estar preparados para dar continuidade à função materna, suprindo as necessidades do bebê quando a mãe, ou cuidador principal, se encontra ausente. Esta função não está relacionada a técnicas, mas a afeto e respeito em relação à criança que está diante de si, sendo necessário supor no bebê a existência de um sujeito que tem o direito de falar, ser ouvido e compreendido em sua condição de desenvolvimento. As necessidades dos bebês não são estáticas, mas se apresentam em transformação constante, o que torna fundamental a presença de um adulto que as perceba e as atenda de forma adequada. Dessa forma, o trabalho realizado com bebês em CEIs deve garantir as condições mínimas necessárias ao desenvolvimento saudável, suplementando e ampliando a função desempenhada pelo cuidador em casa (WINNICOTT, 1975).

É essencial à saúde mental do bebê a vivência de uma relação calorosa, íntima e contínua com a mãe ou com um substituto permanente que desempenhe, de forma regular e constante, o papel materno. Tal condição é prejudicada quando múltiplos educadores se ocupam de seus cuidados, sendo fundamental a particularização no atendimento à criança pequena (BOWLBY, 1988).

Importante ressaltar que o processo de localização da psique no corpo depende tanto da experiência pessoal do bebê, por meio de seus impulsos e sensações corporais, como de tudo que se refere aos cuidados com o corpo. Também está relacionado à satisfação das exigências instintivas que levam à gratificação, o que ressalta a importância do cuidado físico dedicado à criança pelos pais, ou pelos cuidadores das creches, para facilitar a obtenção de um psiquessoma que vá se desenvolvendo de maneira harmônica (WINNICOTT, 1982a).

A permanência do bebê por longos períodos em CEIs torna este ambiente responsável pela maior parte da rotina diária da criança. Cabe a este espaço, portanto, garantir que sua rotina, horários, espaços, atividades e profissionais estejam adequados para a promoção de um desenvolvimento saudável deste que está sob seus cuidados num período da vida que é base para saúde mental (WINNICOTT, 1975).

É evidente que o trabalho com bebês e crianças pequenas em creches requer atenção e cuidados diferenciados daqueles praticados com as crianças maiores, sendo imprescindível o desenvolvimento de estudos nesta área, especialmente numa realidade em que as mães necessitam voltar ao trabalho poucos meses após o nascimento dos filhos. O que é oferecido ao bebê no ambiente de CEI? Defrontamo-nos ainda com diferenças significativas no atendimento oferecido à população de classes sociais diferentes? Se sim, estas diferenças impactam na constituição subjetiva do bebê?

\section{Descrição da Pesquisa Metodologia IRDI: "Uma Intervenção com Educadores a Partir da Psicanálise"}

Este trabalho trata de um recorte da pesquisa "Metodologia IRDI: uma intervenção com educadores a partir da psicanálise" (KUPFER et al., 2009), cujo objetivo consistiu em avaliar a metodologia IRDI, no trabalho de formação de educadoras de Berçário Inicial (B1) e Berçário Final (B2) e na promoção de saúde mental em crianças de 0 a 18 meses que frequentavam instituições de educação infantil.

O IRDI é um instrumento criado pelo Grupo Nacional de Pesquisa (GNP) a pedido do Ministério da Saúde, por meio de uma pesquisa multicêntrica. 
O GNP foi composto por 10 psicanalistas que tinham como objetivo a construção e validação de um protocolo de indicadores de desenvolvimento psíquico para ser utilizado por pediatras e incluído nos protocolos de acompanhamento do desenvolvimento infantil. Este instrumento tem a finalidade de identificar precocemente sinais de entraves no desenvolvimento infantil e de risco psíquico.

O IRDI contém 31 indicadores verificáveis nos primeiros 18 meses de vida da criança, baseados em quatro eixos que balizam a constituição subjetiva: suposição do sujeito, estabelecimento da demanda, alternância presença-ausência e função paterna (KUPFER; BERNARDINO; MARIOTTO, 2014). Esses indicadores se referem a expressões fenomênicas de processos psíquicos. A presença dessas expressões caracteriza um curso saudável do desenvolvimento psíquico. Eles são divididos por faixa etária: $0-4$ meses incompletos; $4-8$ meses incompletos; 8 - 12 meses incompletos e $12-18$ meses. A ausência de 2 ou mais indicadores são considerados sinais de risco de desenvolvimento (KUPFER; BERNARDINO; MARIOTTO, 2014).

Durante o trabalho de campo realizado na pesquisa, dois CEIs foram acompanhados na região do $\mathrm{ABC}$, sendo um da rede conveniada e outro da rede particular, durante um período mínimo de 9 meses. Neste período foram acompanhadas 17 crianças por meio da metodologia IRDI, sendo 7 frequentadoras da rede conveniada, e 10 da rede privada. Foi realizada análise da marcação dos IRDIs destas crianças, bem como da Avaliação Psicanalítica aos 3 anos (AP3) daquelas que foram sorteadas no contexto da pesquisa da qual este trabalho deriva. A AP3 foi utilizada para verificar se as diferenças encontradas nos IRDIs impactaram na constituição subjetiva do bebê, partindo de um referencial psicanalítico, descrevendo e analisando as experiências vivenciadas no ambiente das duas instituições participantes (KUPFER; BERNARDINO; MARIOTTO, 2014).
A AP3 também foi construída pelo GNP, e consiste num roteiro orientador de entrevistas com os pais e a criança, que foi adaptado para o uso em creches. Construída com base nos 4 eixos teóricos do IRDI, possui 4 categorias que abarcam o que é esperado encontrar no funcionamento psíquico de uma criança de 3 anos de idade: o brincar e a fantasia; o corpo e sua imagem; manifestação diante das normas e posição frente à lei; a fala e a posição na linguagem (KUPFER et al., 2009). Permite identificar a presença ou ausência tanto de problemas de desenvolvimento, como de risco psíquico para a constituição do sujeito. A aplicação da AP3 nas crianças sorteadas na pesquisa da qual este estudo deriva teve como objetivo verificar se elas apresentavam ou não sintomas clínicos aos três anos após o acompanhamento com a metodologia IRDI. Partiu-se do pressuposto de que a metodologia IRDI poderia auxiliar os educadores a se tornarem agentes ativos na promoção de saúde mental das crianças sob seus cuidados. Desta forma, eles poderiam colaborar para a redução da incidência de problemas de desenvolvimento, desde aqueles que não interferem no processo de estruturação subjetiva até aos que colocam em risco a instalação do sujeito psíquico. (KUPFER et al., 2009).

O registro da presença ou ausência dos IRDIs, a partir da observação cautelosa das crianças nas creches, serviu tanto para nortear as intervenções realizadas durante o acompanhamento em serviço, quanto as reuniões periódicas com as educadoras. Estas reuniões eram realizadas com o intuito de orientá-las no sentido de tornar presentes os indicadores ausentes.

\section{Resultados e Discussão}

A instituição responsável pela administração da CEI conveniada participante deste estudo é vinculada a entidades religiosas. Atende em seu espaço crianças de 0 a 10 anos. Esta CEI mantém um ambulatório próprio no qual trabalham como voluntários fixos um médico pediatra, uma neuropediatra e uma dentista, 
responsáveis pelo acompanhamento das crianças. Realiza eventos beneficentes para arrecadação de verba, e recebe doações de empresários da região.

As crianças de 5 a 9 anos são atendidas no contra turno da escola que frequentam, na qual permanecem apenas por meio período. Durante o tempo em que permanecem na CEI conveniada, recebem cuidados relacionados à educação, higiene, alimentação e saúde, sendo assessorados por professores.

As crianças de 0 a 5 anos são atendidas em período integral. O berçário é dividido em B1 e B2, porém ambos funcionam no mesmo espaço acomodando crianças de 0 a 18 meses. Durante o acompanhamento decorrente da pesquisa, havia 14 crianças na mesma sala sob responsabilidade de duas educadoras.

O ambiente das crianças consistia em uma grande sala, na qual os berços ficavam alocados próximos a uma parede, as cadeiras de refeição em outra. O centro da sala tinha uma parte ocupada por colchonetes e pneus encapados para uso das crianças que ainda não se deslocavam. Outra parte permanecia sem colchonetes, livre para que as crianças que já andavam ou engatinhavam pudessem se movimentar. Desta forma, os momentos lúdicos, de sono e alimentação ocorriam no mesmo espaço físico. A sala possuía, ainda, uma saída para um parque externo de uso exclusivo dos bebês e acesso à área de banho, também exclusiva.

Desde os primeiros dias na creche, a criança era recebida na porta pelas educadoras, não havendo espaço para a permanência dos pais em sala de aula durante o período de adaptação. Observou-se uma tolerância maior em relação ao uso de chupeta, paninhos ou de objetos transicionais pela criança no período de adaptação. Porém, o objetivo claro era de retirar esses objetos o mais rápido possível, por uma questão de higiene (para que as crianças não ficassem trocando de chupeta), de autonomia (eles precisavam amadurecer) e de socialização (os pertences da creche são de todos, não havendo espaço para bens pessoais).
A partir da observação e das reuniões com as educadoras foi possível verificar um padrão de rotina ao qual as crianças necessariamente precisavam se adaptar. As crianças tinham horário fixo para entrar e sair da creche, que funcionava com período integral, com exceções pontuais em caso de necessidade específica, como saúde por exemplo. O horário de permanência da criança era das 7:30h as 16:30h. Faltas por mais de 15 dias sem justificativa de saúde implicaria em perda da vaga.

A alimentação era oferecida em horários específicos determinados pela creche, independente da rotina da criança anterior a sua entrada. As crianças eram alimentadas concomitantemente pelas educadoras ( 1 para cada 7 crianças), auxiliadas por volantes (funcionárias que se revezam nas salas da CEI, conforme a necessidade). Normalmente, as educadoras alimentavam cerca de 4 crianças ao mesmo tempo. Em caso de bebês que precisavam ser alimentados no colo, começavam por aquele que estivesse reivindicando o alimento com mais intensidade.

O momento do sono também era coletivo, logo após o almoço, com um tempo máximo determinado. As educadoras dispensavam maior atenção àqueles que apresentavam maior dificuldade em dormir no horário estabelecido, até que se adaptassem e dormissem sozinhos. A atenção observada consistia em carinho ou leves tapinhas nas costas, canção de ninar e até mesmo chamadas de atenção para que se mantivessem em silêncio.

O horário do banho era fixo, e realizado uma vez ao dia. Por ser considerada uma atividade fisicamente mais cansativa as educadoras se revezavam nesta função. A necessidade de troca de fraldas era verificada na hora do banho, logo após o sono. As crianças que estivessem mais sujas eram as primeiras a tomarem banho. Caso a criança necessitasse, as trocas de fraldas eram realizadas em outros momentos.

A rotina organizava-se da seguinte forma: entrada às 7:30h; café da manhã às $8 h$; banho às $9: 30 h$. Todos 
deveriam estar banhados até às 10:30h, horário do almoço. Às $11 \mathrm{~h}$ era a hora do sono, às $13 \mathrm{~h}$ o lanche da tarde e às 15:30h o jantar. A este padrão de rotina as crianças precisavam necessariamente se adaptar.

As atividades lúdicas eram oferecidas em momentos específicos: a hora do parque, a hora da bola, a hora dos livros, dentre outras. Atividades pedagógicas como aulas de música, leitura de histórias e momentos de estimulação motora faziam parte da programação semanal das atividades dos bebês e crianças pequenas.

O acompanhamento em serviço e as reuniões mensais realizadas com as educadoras permitiu a observação de como estas se percebiam no cuidado com as crianças e estabeleciam a relação com as mesmas. Os cuidados de higiene eram percebidos como uma parte inevitável do cuidado com o bebê e com a criança pequena, mas não como uma oportunidade de individualização da relação com o mesmo, sendo realizada, na maioria das vezes, de forma mecânica e apressada. Com algumas crianças, normalmente aquelas com as quais as educadoras mais se identificavam, ou "adotavam", elas conseguiam exercer uma função maternante.

As 2 educadoras responsáveis pela sala demonstraram engajamento em seu trabalho e nos cuidados com as crianças. Também foi possível observar expressões de carinho e afeto pela maioria, além de compaixão pelas condições precárias em que a algumas viviam. Porém, havia poucos momentos em que conseguiam se sentar simplesmente para brincar com as crianças em virtude da intensa e constante demanda de cuidados de higiene e segurança das mesmas. Ambas relatavam ser um trabalho fisicamente cansativo.

Era clara a valorização da formação das educadoras em geral, sendo reservada a última sexta-feira do mês para participação destas em cursos oferecidos na própria instituição. Este momento também era utilizado para resolver assuntos administrativos e para culto religioso.
A visão assistencialista e pedagógica do papel das educadoras nos cuidados com os bebês foi predominante, modificando-se ao longo do acompanhamento em serviço.

\section{Centro de Educação Infantil da rede particular}

A instituição particular participante deste estudo, também vinculada a uma entidade religiosa, atende crianças e adolescentes desde o berçário até o $3^{\circ}$ ano do Ensino Médio. A construção do berçário era recente na época da pesquisa, datado do ano anterior, com capacidade para atender 30 crianças de 0 a 18 meses. Na época do acompanhamento, havia 10 crianças com 3 educadoras.

Enquanto as crianças maiores de 18 meses até o Ensino Médio possuíam uma rotina fixa e rígida de horário de entrada e saída a serem cumpridos, os bebês do berçário desfrutavam de outras possiblidades. Contavam com horário flexível de entrada e saída, de acordo com a necessidade dos pais. Porém, a maioria dos bebês permanecia de 9 a 12 horas no berçário, que funcionava das $7 \mathrm{~h}$ às $19 \mathrm{~h}$. Uma das educadoras era obrigada a permanecer com a criança após este horário caso os pais se atrasassem.

O berçário desta instituição contava com um espaço dividido em 5 partes. Havia uma parte central, maior, onde ficavam os brinquedos e espaços acolchoados para as crianças brincarem, bem como as cadeirinhas de ninar e armários com seus pertences. Este espaço maior tinha uma divisão para quando fosse necessário separar as crianças que já andavam das que ainda não o faziam.

Separado por uma porta de vidro, ficava o espaço do sono, com os berços. Sempre que havia uma criança dormindo a porta permanecia fechada, mas a educadora podia monitorar tanto pelo vidro como pela babá eletrônica o momento em que os bebês despertassem. Em outros dois espaços, separados por um portãozinho vazado do espaço central maior, ficavam as cadeiras de alimentação 
e a cozinha. As educadoras tinham a disposição frutas, leite, biscoitos e outros alimentos específicos de cada criança para quando precisassem. O último espaço, bem reservado e sem visibilidade para a área central, era a área do banho. Nesta área, a educadora tinha a oportunidade de estar totalmente a sós com o bebê, sem se preocupar com o que se passava em outros espaços.

Durante os primeiros dias da criança no berçário era solicitado que a mãe, o pai ou outro cuidador principal da criança permanecessem na sala ou no ambiente da escola pelo período de estada do(a) filho(a), que somavam duas horas diárias durante a primeira semana, aumentando gradativamente nas semanas subsequentes. Havia certa flexibilidade com as crianças que apresentavam maior dificuldade de adaptação, sendo permitida a entrada dos pais por período maior que o usual. Porém, estas exceções incomodavam as educadoras, que relatavam sentimentos de serem fiscalizadas com a presença prolongada dos pais no ambiente do berçário.

O uso de chupetas, paninhos e objetos de apego trazidos de casa eram permitidos e até mesmo incentivados. Eram utilizados com frequência como recurso para evitar o choro da criança, tanto no período de adaptação quanto no restante do ano letivo.

A supracitada pesquisa, da qual este trabalho constitui um recorte, contou com a participação de apenas um berçário da rede particular. A partir da observação e das reuniões com as educadoras, foi possível verificar a existência de uma rotina com os bebês dotada de certa flexibilidade, na qual se buscava adequar a necessidade da criança à organização do berçário.

Conforme citado anteriormente, os horários de entrada e saída das crianças eram variáveis, de acordo com a rotina e a necessidade de cada família. A criança poderia permanecer no CEI período integral, das $7 \mathrm{~h}$ às $19 \mathrm{~h}$, ou períodos de horas ao longo do dia. Mas, na maioria dos casos a criança permanecia por período integral.
Além disso, a alimentação era oferecida num período específico do dia, determinado pelo CEI, dentro do qual a criança era alimentada no momento em que demonstrasse fome e de acordo com a rotina iniciada em casa. Caso a criança estivesse dormindo, por exemplo, ou houvesse registro na agenda de ter sido alimentada em casa pouco tempo antes da hora do almoço, este era oferecido posteriormente. A permanência de uma educadora para cada 4 crianças e a manutenção da rotina alimentar da família, facilitava o momento da alimentação, realizada de maneira mais individualizada, sendo necessário auxílio de funcionário externo ao berçário apenas na falta de uma delas.

Da mesma forma, as crianças eram colocadas para dormir de acordo com seu próprio ritmo. Esta possibilidade era facilitada pelo fato do ambiente dos berços ser separado da área na qual as crianças permanecem enquanto acordadas, mantendo o ambiente silencioso e mais escuro.

Não eram todas as crianças que tomavam banho neste berçário, apenas aquelas que permaneciam no integral ou cujas mães solicitavam e/ou autorizavam. Observou-se certo receio das educadoras em dar o banho em algumas crianças cujas mães não autorizavam, ou não haviam incluído no pacote fechado pela escola, mesmo que este se mostrasse necessário. A justificativa verbalizada era a evitação de possíveis represálias ou reclamações das mães ou da própria escola. O horário do banho ocorria na parte da tarde, mas poderia ocorrer em outros momentos em que a criança estivesse muito suja e as educadoras julgassem necessário. Os banhos eram dados individualmente, com a participação de todas as educadoras, muitas vezes sendo realizado pela educadora de preferência da criança. As trocas de fraldas eram realizadas de acordo com a necessidade da criança.

Não havia momentos de atividades lúdicas pré-programadas. Os brinquedos e materiais permaneciam ao alcance das crianças, ou em prateleiras, sendo possível às mesmas pegarem ou 
solicitarem às educadoras os objetos que desejassem. Durante todo tempo, a televisão permanecia ligada e algumas crianças permaneciam períodos mais prolongados em frente à mesma, assistindo aos DVDs de desenhos ou clips de músicas infantis.

$\mathrm{O}$ acompanhamento em serviço e as reuniões mensais realizadas com as educadoras permitiu a observação de como estas se percebiam no cuidado com as crianças e estabeleciam a relação com as mesmas. Observou-se uma preocupação especial em não permitir que o bebê chorasse por muito tempo sem assistência. Tal preocupação esteve presente especialmente por dois fatores principais verbalizados pelas educadoras: 1) pelo fato do berçário estar localizado próximo à recepção do Colégio e o choro poder ser escutado pelas funcionárias e outros pais que eventualmente estivessem presentes na recepção. Temiam que estes pensassem que os bebês estivessem sendo maltratados, ou que eram más profissionais; 2) pelo fato de que a qualquer momento poderia ocorrer uma visita de novos pais ao berçário, e estes não poderiam ver os bebês chorando para não terem uma má impressão.

As educadoras demonstraram intensa preocupação e ansiedade em atender às expectativas dos pais e da instituição, mesmo estando em discordância com o que deveria ser feito. $\mathrm{O}$ receio de reclamações por parte dos pais, de serem repreendidas pela instituição, ou até mesmo de perderem seus empregos em virtude de algum malentendido era constantemente presente. Apesar das educadoras se mostrarem engajadas nos cuidados com as crianças, a preocupação predominante era de agradar aos pais e à própria instituição.

Não havia programa de formação fornecido pela instituição, apesar da percepção por parte da coordenação da importância e necessidade do mesmo, pois isto acarretaria pagamento de horas extras não aprovadas pela diretoria. Em relação à importância dos cuidados de higiene, não foi observado diferença em relação à percepção das educadoras da creche conveniada.
Não foram observadas atividades pedagógicas dirigidas. As educadoras permaneciam o tempo todo com as crianças, cuidando e brincando com o que elas demonstrassem interesse. Como havia menor número de crianças por educadora, era possível a convocação de bebês que permanecessem mais quietinhos para interagir com elas e um tempo maior dedicado às trocas afetivas. Porém, as trocas afetivas eram dirigidas de forma mais espontânea e constante às crianças com as quais as educadoras se identificavam, e menos àquelas que choravam mais, aparentemente pelo fato de tornarem o trabalho mais extenuante pela preocupação em calar o choro.

Neste CEI, não foi observado predomínio de uma visão assistencialista ou pedagógica, mas uma necessidade de cuidar das crianças de maneira a agradar os pais e a instituição, em alguns momentos perdendo-se o olhar para as necessidades da criança.

\section{Acompanhamento dos Bebês Através do IRDI}

Os 17 bebês de ambas as instituições foram acompanhados semanalmente através dos IRDIs. A identificação dos indicadores ausentes, que sinalizavam risco de desenvolvimento dos bebês, norteavam as intervenções realizadas com as educadoras. Estas intervenções tinham o objetivo de presentificar estes indicadores, evitando a cristalização de possíveis quadros psicopatológicos.

O procedimento ético junto aos bebês cujos indicadores ausentes não se tornassem presentes com as intervenções realizadas junto às educadoras era convidar os pais para uma conversa e realizar o encaminhamento para o atendimento psicanalítico por outra pesquisadora, participante da pesquisa. Dos 17 bebês acompanhados nestas instituições, foi necessário o encaminhamento de apenas um bebê, que frequentava o CEI da rede conveniada e apresentava ausência de vários indicadores de risco psíquico. 
Tabela 1 - $1^{\text {a }}$ marcação IRDI de indicadores ausentes em porcentagem

\begin{tabular}{|c|c|c|c|c|c|c|}
\hline \multirow[t]{2}{*}{ Indicador/Instituição } & \multicolumn{3}{|c|}{ Conveniada } & \multicolumn{3}{|c|}{ Particular } \\
\hline & Ausente & Presente & $\mathrm{NA} / \mathrm{NV}$ & Ausente & Presente & $\mathrm{NA} / \mathrm{NV}$ \\
\hline $\begin{array}{l}1 \text { Quando a criança chora ou grita, a professora } \\
\text { sabe o que ela quer }(\mathrm{S} / \mathrm{S})\end{array}$ & 0 & 57 & 43 & 20 & 40 & 40 \\
\hline $\begin{array}{l}4 \text { A professora propõe algo à criança e aguarda } \\
\text { a sua reação (ED) }\end{array}$ & 14 & 29 & 57 & 10 & 40 & 50 \\
\hline $\begin{array}{l}5 \text { Há trocas de olhares entre a criança e a } \\
\text { professora. }(\mathrm{P} / \mathrm{A})\end{array}$ & 0 & 86 & 14 & 10 & 80 & 10 \\
\hline 6 A criança adapta-se a rotina da creche (ED) & 14 & 86 & 0 & 50 & 30 & 20 \\
\hline $\begin{array}{l}7 \text { A criança utiliza sinais diferentes para } \\
\text { expressar suas diferentes necessidades (ED) }\end{array}$ & 57 & 14 & 29 & 30 & 30 & 40 \\
\hline $\begin{array}{l}8 \text { A criança solicita a professora e faz um } \\
\text { intervalo para aguardar sua resposta (P/A) }\end{array}$ & 43 & 43 & 14 & 30 & 30 & 40 \\
\hline $\begin{array}{l}22 \text { A criança aceita alimentação semi-sólida, } \\
\text { sólida e variada (ED) }\end{array}$ & 14 & 57 & 29 & 20 & 40 & 40 \\
\hline $\begin{array}{l}24 \text { A criança suporta bem as breves ausências da } \\
\text { professora e reage às ausências prolongadas (FP) }\end{array}$ & 14 & 0 & 86 & 10 & 0 & 80 \\
\hline $\begin{array}{l}26 \text { A professora já não se sente mais obrigada a } \\
\text { satisfazer tudo que a criança pede (FP) }\end{array}$ & 0 & 14 & 86 & 10 & 0 & 80 \\
\hline
\end{tabular}

Fonte: Autores.

Observou-se no CEI da rede conveniada 6 indicadores de risco de desenvolvimento psíquico ausentes $(4,6,7,8,22,24)$, sendo quatro deles do eixo teórico estabelecimento da demanda, um do eixo alternância presença/ausência e um do eixo função paterna. No CEI da rede particular foi observada a ausência de 9 indicadores $(1,4,5,6,7$, $8,22,24,26)$, sendo um deles o único referente ao eixo suposição do sujeito, 3 do eixo estabelecimento da demanda, 3 do eixo alternância presençal ausência e 2 do eixo função paterna.

Interessante notar que, apesar do CEI da rede privada oferecer uma rotina mais individualizada às necessidades da criança e disponibilizar uma proporção mais favorável da quantidade de educadores por bebê, encontramos ausente o único indicador do eixo suposição do sujeito, indicativo de risco psíquico: "quando a criança chora ou grita a professora sabe o que ela quer". A ausência deste indicador parece estar relacionada com a necessidade observada, por parte das educadoras, em calar este choro o mais rápido possível para que pais ou outros funcionários não o escutem, recorrendo a chupetas e paninhos sem se ocuparem do tempo necessário à compreensão do que a criança quer comunicar através deste choro. Desta forma, fica comprometida a possibilidade de antecipação, pelo educador, de um sujeito psíquico no bebê, antecipação esta fundamental para a construção da subjetividade (KUPFER et al., 2009).

No CEI conveniado, 4 dos 6 indicadores encontrados ausentes estavam relacionados ao eixo teórico estabelecimento da demanda. Neste eixo, as reações da criança, como o choro, por exemplo, são 
reconhecidas pela professora como um pedido que a criança dirige a ela, o que permite a construção de uma demanda, uma demanda de amor, que este sujeito dirigirá a todos com quem vier a se relacionar (KUPFER et al., 2009). O excesso de trabalho vivido pelas educadoras, a necessidade de atender a uma rotina rígida de horários referentes aos cuidados com as crianças, somado a visão assistencialista e pedagógica predominantes, não deixam espaço ou tempo para o reconhecimento das demandas das crianças.

Apesar de contar com uma rotina mais flexível e com maior número de educadoras por criança, o fato do atendimento das educadoras no CEI da rede privada estar voltado prioritariamente ao atendimento das necessidades e anseios dos pais e da própria instituição, pareceu dificultar não apenas o reconhecimento e atendimento das demandas dos bebês, mas também a possibilidade de aparecimento da resposta por parte da criança verificada na ausência de 4 indicadores do eixo alternância presença-ausência. Não se cria, desta forma, um intervalo entre a demanda da criança e a experiência de satisfação no qual a resposta da criança pode emergir e que será base para as demandas e respostas futuras (KUPFER et al., 2009). A única resposta esperada é a cessação do choro.

Os indicadores 24 e 26 referentes ao eixo função paterna, encarregada de transmitir os parâmetros sociais e culturais (KUPFER et al., 2009) e encontrados ausentes em ambas as CEIs, foram observados nas crianças que possuíam uma educadora de referência e apresentavam dificuldade em se separarem das mesmas. Na CEI da rede privada observou-se ainda o indicador 26 ausente, pois, de fato, as educadoras esforçavam-se em não contrariar as crianças para que as mesmas permanecessem sem chorar.

A análise da marcação dos IRDIs ao final da pesquisa permite verificar as diferenças na presença ou ausência dos indicadores nas crianças acompanhadas nas duas instituições, após o acompanhamento em serviço.

Tabela 2 - marcação final IRDI de indicadores ausentes em porcentagem

\section{Indicador/Instituição}

7 A criança utiliza sinais diferentes para expressar suas diferentes necessidades (ED)

8 A criança solicita a professora e faz um intervalo para aguardar sua resposta $(\mathrm{P} / \mathrm{A})$

22 A criança aceita alimentação semi-sólida, sólida e variada $(\mathrm{P} / \mathrm{A})$

24 A criança suporta bem as breves ausências da professora e reage às ausências prolongadas (FP)

26 A professora já não se sente mais obrigada a satisfazer tudo que a criança pede (FP)

\begin{tabular}{|llllll|}
\hline \multicolumn{2}{l}{ Conveniada } & \multicolumn{4}{l}{ Particular } \\
\hline Ausente & Presente & NA/NV & Ausente & Presente & NA/NV \\
14 & 86 & 0 & 0 & 100 & 0 \\
\hline
\end{tabular}

0

100

$0 \quad 10$

90

0

$\begin{array}{llllll}14 & 86 & 0 & 10 & 80 & 10\end{array}$

14

140

100

$100 \quad 0$

40

50

40

$60 \quad 0$

1

Fonte: Autores.

A tabela acima permite verificar que, ao final, a grande maioria dos indicadores puderam ser verificados nas crianças participantes da pesquisa, nas duas instituições, bem como uma redução na quantidade de indicadores ausentes. 
No CEI conveniado, observamos ainda a ausência de 3 indicadores (7, 22 e 24) dos eixos estabelecimento da demanda, alternância presença/ ausência e função paterna, respectivamente. Observa-se uma porcentagem elevada de ausência do indicador 24, provavelmente relacionada ao fato da maioria das crianças não possuir uma educadora de preferência, recorrendo a que permanece presente na ausência de uma delas. Na ocasião da observação, uma das educadoras machucou o pé e precisou se afastar por 2 meses. Foi observada reação à ausência prolongada apenas em relação às crianças que mantinham com ela uma relação de preferência.

Já no CEI da rede privada, encontramos a ausência de 4 indicadores $(8,22,24$ e 26), sendo 2 do eixo alternância presença/ausência e 2 do eixo função paterna, respectivamente. Observa-se um índice de ausência mais elevado nos indicadores referentes ao eixo função paterna. Apesar dos avanços alcançados no acompanhamento em serviço das educadoras em relação a percepção de sua importância como agente de promoção de saúde mental dos bebês sob seus cuidados e no aproveitamento das condições de trabalho e de particularização dos bebês, ainda permanece fortemente presente a necessidade de atender e agradar aos pais das crianças e a própria instituição. Desta forma, as professoras tendem a atender todos os desejos das crianças que mais se manifestam através do choro ou da birra, na tentativa de evitar tais manifestações.

Ao longo do acompanhamento das crianças, apenas uma, do CEI conveniado, foi encaminhada para atendimento individual junto a seus pais. $\mathrm{O}$ encaminhamento se deu durante o trabalho de acompanhamento em serviço ao se perceber que, apesar das intervenções junto às educadoras, os indicadores ausentes não se presentificavam. Ao final da pesquisa, apesar da criança ainda estar em atendimento individual com seus pais, os indicadores já haviam se presentificado.
Das 17 crianças acompanhadas com a Metodologia IRDI, 7 delas foram sorteadas na $2^{\text {a }}$ etapa da pesquisa para participarem da Avaliação Psicanalítica aos 3 anos (AP3). Destas, 4 pertenciam ao CEI da rede privada e 3 ao CEI conveniado. Das 7 crianças submetidas à AP3, nenhuma delas apresentou sinais de risco psíquico.

\section{Considerações Finais}

Os primeiros anos da infância são decisivos para desenvolvimento cognitivo, afetivo, social e, principalmente, psíquico. Por este motivo, oferecer aos bebês e crianças pequenas o melhor cuidado possível é fundamental. Os CEIs, como parte da Educação Infantil, vêm se constituindo no mundo contemporâneo como um espaço de educação coletiva com caráter pedagógico, apesar de ainda ser possível observar resquícios do caráter assistencialista nos CEIs que atendem as classes menos favorecidas.

Com o aumento da busca por CEIs e a longa permanência a que estão submetidas as crianças, não cabe mais somente à família a função de inserir seus filhos na cultura. Os CEIs partilham com a família essa função em decorrência da entrada das mulheres no mercado de trabalho, das novas configurações familiares, além de uma maior conscientização de que este é um espaço rico para a socialização e o desenvolvimento da criança pequena. Passam a ter importante participação e responsabilidade na formação das crianças enquanto sujeitos.

Apesar das diferenças encontradas nos cuidados com os bebês e crianças pequenas oferecidos nos CEIs da rede privada e conveniada, observa-se a obediência a uma lógica institucionalizada nos padrões da pedagogia escolar que se impõe sobre as crianças e sobre os educadores que vivem grande parte do tempo de suas vidas nesta instituição. As regras e condições de cuidados com as crianças são organizadas como uma estrutura externa que não considera todos os sujeitos envolvidos - 
educadores, crianças e suas famílias - mas sim a ordem, as aparências, a garantia da realização das tarefas relacionadas à higiene, saúde e segurança. Os CEIs precisam se adaptar às necessidades das crianças, de acordo com as especificidades de cada faixa etária, não ao contrário. Neste sentido, faz-se necessário pesquisas futuras que tenham o objetivo de desenvolver estratégias de gestão de creches que auxiliem na promoção do desenvolvimento infantil.

Sem dúvidas, foram observadas diferenças significativas nos cuidados oferecidos às crianças nas duas realidades observadas. Da mesma forma, pode-se constatar que, cada uma dentro de sua peculiaridade, apresenta fatores institucionais que podem dificultar a construção subjetiva da criança. O lugar ocupado pelo bebê no discurso institucional, mostrou-se semelhante. Em ambas as CEIs, o cuidado ao bebê era pensado em função da rotina institucional e de demandas organizativas - sejam elas pedagógicas, assistenciais ou econômicas - relegando a segundo plano o bebê e suas necessidades enquanto sujeito neste período inicial da vida. Tal realidade impacta no que se propõe como foco de trabalho da CEI e dificulta que a relação singular estabelecida entre o bebê e o educador seja reconhecida como parte fundamental e valiosa na atenção ofertada ao bebê no ambiente educativo.

O acompanhamento pelos IRDIs possibilitou uma leitura do laço ofertado ao bebê na CEI, de modo a balizar uma intervenção que privilegiasse as respostas singulares do bebê dentro de um ambiente coletivo. Ao destacar essa dimensão, que fica secundarizada pela razão organizativa das instituições, o presente estudo colabora para evidenciar a importância da dimensão subjetivante do trabalho educativo com bebês. Como resultado, obtivemos que o acompanhamento em serviço por meio da metodologia IRDI, mostrou-se um potente modo de intervenção no ambiente escolar ao se considerar a articulação entre constituição subjetiva e promoção de saúde mental nesse momento da vida.

\section{Referências}

ABRAMOWICZ, A.; WASKOP, G. Creches: atividades para crianças de zero a seis anos. São Paulo: Moderna, 1995.

BALABAN, N. Separation: an oportunity for growth. 1988. Disponível em: <https://files.eric.ed.gov/fulltext/ ED297867.pdf>. Acesso em: 20 set. 2017.

BLOOM-FESHBACH, S.; BLOOM-FESHBACH, J.; GAUGHRAN, J. The child's tie to both parents: separation paterns and nursery school adjustment. American Journal of Orthopsychiatry, Menasha, v. 50, n. 3, p. 505-521, jul. 1980.

BOWLBY, J. Cuidados maternos e saúde mental. São Paulo: M. Fontes, 1988.

BOWLBY, J. Uma base segura: aplicações clínicas da teoria do apego. Porto Alegre: Artes Médicas, 1989.

BRASIL. Lei n. 9396/96, de 20 de dezembro de 1996. Estabelece as diretrizes e bases da educação nacional. 1996. Disponível em: <https://www.jusbrasil.com. br/topicos/12073290/lei-n-9396-de-20-de-dezembrode-1996>. Acesso em: 27 ago. 2017.

BRASIL. Ministério da Educação. Educação infantil: número de crianças em creches cresce $150 \%$ em uma década. 2012. Disponível em: <http://portal.mec.gov. br/ultimas-noticias/207-1625150495/17753-numerode-criancas-em-creches-cresce-150-em-uma-decada>. Acesso em: 15 mar. 2018

CAMPOS, M. M.; ROSEMBERG, F.; FERREIRA, I. M. Creches e pré-escolas no Brasil. São Paulo: Cortez, 1993.

CATALDI, M. C. C. Modificações sociais e a participação da mulher no mercado de trabalho. In GAYOTTO, M. L. C. (Org.). Creches: desafios e contradições da criação da criança pequena. São Paulo: Ícone, 1992. p. 23-24.

CIVILETTI, M. V. P. O cuidado da criança pequena no Brasil escravista. Cadernos de Pesquisa, São Paulo, v. 76, n. 1, p. 31-40, fev. 1991. Disponível em: $<$ http://publicacoes.fcc.org.br/ojs/index.php/cp/article/ view/1052/1060>. Acesso em: 14 set. 2017.

DAVIES, J.; BREMBER, I. The effects of gender and attendande period on children's adjustment to nursery classes. British Educational Research Journal, London, v. 17, n. 1, p. 73-82, fev. 1991.

DIEESE - Departamento Intersindical de Estatística e Estudos Socioeconômicos. Anuário dos trabalhadores. 8. ed. São Paulo, 2007. Disponível em: <https://www. dieese.org.br/anuario/2007/anuario2007.html>. Acesso em: 26 dez. 2015. 
FARIA, S. C. História e políticas de educação infantil. In: FAZOLO, E. (Org.). Educação infantil em curso. Rio de Janeiro: Ravil, 1997. p. 9-37.

IBGE. Sistema IBGE de Recuperação AutomáticaSIDRA. Censo demográfico 2010. Disponível em: $<$ http://www.censo2010. ibge.gov.br/>. Acesso em: 26 dez. 2015.

KUPFER, M. C. M. et al. Valor preditivo de indicadores clínicos de risco para o desenvolvimento infantil: um estudo a partir da teoria psicanalítica. Latin American Journal of Fundamental Psychopathology, São Paulo, v. 6, n. 1, p. 48-68, maio, 2009. Disponível em: <http:// www.psicopatologiafundamental.org/uploads/files/ latin_american/v6_n1/valor_preditivo_de_indicadores clinicos_de_risco_para_o_desenvolvimento_infantil.pdf $>$ Acesso em: 3 ago. 2017.

KUPFER, M. C. M.; BERNARDINO, L. M.; MARIOTTO, R. M. M. De bebê a sujeito: a metodologia IRDI nas creches. São Paulo: Escuta/ FAPESP, 2014.

MARIOTTO, R. M. M. Cuidar, educar e prevenir: as funções da creche na subjetivação de bebês. São Paulo: Escuta, 2009.

OLIVEIRA, Z. M. R. A creche no Brasil: mapeamento de uma trajetória. Revista da Faculdade de Educação, São Paulo, v. 14, n. 1, p. 43-52, jan./jun. 1988. Disponível em: <http://www.revistas.usp.br/rfe/article/ view/33402/36140>. Acesso em: 20 ago. 2016.

OLIVEIRA, Z. M. R. et al. Creches: crianças, faz de conta \& cia. Petrópolis: Vozes, 1992.

RAPOPORT, A.; PICCININI, C. A. Concepções de educadoras sobre a adaptação de bebês à creche. Psicologia: Teoria e Pesquisa, Brasília, v. 17, n. 1, p. 6978, jan./abr. 2001. Disponível em: <https://www.lume. ufrgs.br/bitstream/handle/10183/19697/000386477. pdf? sequence $=1>$. Acesso em: 28 jul. 2017.

ROSEMBERG, F. (Org.). Creche. São Paulo: Cortez, 1989.
SÃO PAULO. Prefeitura Municipal. Secretaria Municipal da Educação. Portaria n. 3477, de 8 de julho de 2011. Institui normas gerais para celebração de convênios no âmbito da Secretaria. Disponível em: <http://www3. prefeitura.sp.gov.br/cadlem/secretarias/negocios juridicos/cadlem/integra.asp?alt $=09072011 \mathrm{P} \% 20$ 034772011SME>. Acesso em: 17 jun. 2017.

SPITZ, R. A. Hospitalism: an inquiry into the genesis of psychiatric condition in early childhood (I). Psychoanal Study Child, Bethesda, v. 1, p. 53-74, 1945.

SPITZ, R.A. O primeiro ano de vida: um estudo psicanalítico do desenvolvimento normal e anômalo das relações objetais. São Paulo: M. Fontes, 1980.

VASCONCELOS, C. R. F. et al. A incompletude como virtude: interação de bebês na creche. Psicologia: Reflexão e Crítica, Porto Alegre, v.16, n. 2, p. 293-301, 2003. Disponível em: <http://www.scielo.br/scielo. php?pid=S0102-79722003000200009\& script $=$ sci abstract\&tlng=pt $>$ Acesso em: 25 jul. 2017.

VERNY, T. R.; WEINTRAUB, P. O bebê do amanhã: um novo paradigma para a criação dos filhos. São Paulo: Barany, 2014.

WINNICOTT, D. W. A integração do ego no desenvolvimento da criança. In: $O$ ambiente e os processos de maturação: estudos sobre a teoria do desenvolvimento emocional. Porto Alegre: Artes Médicas, 1982a. Cap. 4, p. 55-61.

WINNICOTT, D. W. A mãe, a professora e as necessidades da criança. In: A criança e seu mundo. Rio de Janeiro: Zahar, 1975. Cap. 28, p. 214-224.

WINNICOTT, D. W. Desenvolvimento emocional primitivo. In: (Org.). Textos selecionados: da pediatria à psicanálise. 2. ed. Rio de Janeiro: F. Alves, 1978. p. 269-285.

WINNICOTT, D. W. Teoria do relacionamento paternoinfantil. In: $O$ ambiente e os processos de maturação: estudos sobre a teoria do desenvolvimento emocional. Porto Alegre: Artes Médicas, 1982b. Cap. 3, p. $38-54$. 